\title{
Performance of a Fly Ash Geopolymeric Mortar for Coating of Ordinary Portland Cement Concrete Exposed to Harsh Chemical Environments
}

\author{
Walid Tahri ${ }^{1, a}$, Zahra Abdollahnejad ${ }^{2, b *}$, Jorge Mendes ${ }^{3, c}$, \\ Fernando Pacheco-Torgal ${ }^{4, d}$ and José Barroso de Aguiar ${ }^{5, e}$ \\ ${ }^{1}$ University of Sfax, Tunisia \\ ${ }^{2,4,5}$ C-TAC Research Centre, University of Minho, Portugal \\ ${ }^{3}$ Civil Engineering Department, University of Minho, Portugal \\ awalidtahri1980@yahoo.fr, 'tolumahvash@gmail.com, 'a50834@alunos.uminho.pt, \\ torgal@civil.uminho.pt, daguiar@civil.uminho.pt
}

\begin{abstract}
Keywords: Concrete infrastructures; Portland cement concrete; geopolymers; coatings; acid attack
\end{abstract}

\begin{abstract}
Premature degradation of ordinary Portland cement (OPC) concrete infrastructures is a current and serious problem with overwhelming costs amounting to several trillion dollars. The use of concrete surface treatments with waterproofing materials to prevent the access of aggressive substances is an important way of enhancing concrete durability. The most common surface treatments use polymeric resins based on epoxy, silicone (siloxane), acrylics, polyurethanes or polymethacrylate. However, epoxy resins have low resistance to ultraviolet radiation while polyurethanes are sensitive to high alkalinity environments. Geopolymers constitute a group of materials with high resistance to chemical attack that could also be used for coating of concrete infrastructures exposed to harsh chemical environments.

This article presents results of an experimental investigation on the resistance to chemical attack (by sulfuric and nitric acid) of several materials: OPC concrete, high performance concrete (HPC), epoxy resin, acrylic painting and a fly ash based geopolymeric mortar. Three types of acids, each with high concentrations of $10 \%, 20 \%$ and $30 \%$, were used to simulate long term degradation by chemical attack. The results show that the epoxy resin had the best resistance to chemical attack, irrespective of the acid type and acid concentration.
\end{abstract}

\section{Introduction}

Premature degradation of OPC concrete infra-structures is a current and serious problem related to the fact that OPC concrete presents a higher permeability that allows water and other aggressive elements to enter, leading to carbonation and chloride ion attack resulting in corrosion problems [1].

Pacheco-Torgal et al. [2] mentioned the case of a tunnel in Dubai, which have been concluded in 1975 and needed to be completely repaired just after 11 years a case of pile foundations disintegrated just after 12 years, and also a study on Norway OPC concrete bridges which indicate that several presented corrosion problems 24 years after they were built. As a consequence worldwide concrete infrastructure rehabilitation costs are staggering. In the European Union nearly 84,000 reinforced and prestressed concrete bridges require maintenance, repair and strengthening with an annual budget of $£ 215 \mathrm{M}$, and that estimate does not include traffic management cost [3].

Many of the degraded concrete structures were built decades ago when little attention was given to durability issues. Concrete durability means above all minimizing the possibility of aggressive elements to enter the concrete, under certain environmental conditions for any of the following transport mechanisms: permeability, diffusion or capillarity. The use of concrete surface treatments with waterproofing materials (also known as sealers) to prevent the access of aggressive substances is an important way of contributing to concrete durability. 
Almusallam et al [4] studied several concrete coatings concluding that epoxy and polyurethane coatings performed better than acrylic, polymer and chlorinated rubber coatings.

Other authors $[5,6]$ showed that although some waterproof materials are effective for a particular transport mechanism (diffusion, capillarity, permeability) cannot be for another. They compared the waterproofing capacity of concrete with three polymeric resins (epoxy, silicone, acrylic) and mentioned that the silicone based is more effective $(99.2 \%)$ in reducing water absorption by capillarity than the epoxy resin (93.6\%), but in terms of chloride diffusion the epoxy resin is $100 \%$ effective, while the silicone varnish does not go beyond 67.5\%. Epoxy coatings exhibited excellent durability under the laboratory and field test conditions and are recommended for protecting concrete in cooling tower basins against sulphur oxidising or other acid producing bacteria [7].

Medeiros \& Helene [8] used a water repellent material based on silane-siloxane noticing that although it is effective to reduce the water absorption by capillarity of concrete (reduced from 2 to 7 times), it only managed to achieve a reduction of the chloride diffusion from $11 \%$ to $17 \%$ and also failed to prevent the access of water by permeability.

Pacheco-Torgal and Jalali [9] confirm that the surface treatment of concrete with a water repellent material is effective, but above all more cost-effective when compared with the alternative of using a polymer additive in the composition of concrete.

Recently Brenna et al [10] study The efficiency of four commercial concrete coatings (a polymer modified cementitious mortar and three elastomeric coatings) against chloride-induced corrosion concluding that the polymer containing mortar shows the best effect on delay chlorides penetration in concrete.In summary the most common surface treatments use polymeric resins based on epoxy, silicone (siloxane), acrylics, chlorinated rubber, polyurethanes or polymethacrylate.

Bijen [11] mentioned that the epoxy resins have low resistance to ultraviolet radiation and polyurethanes are sensitive to high alkalinity environments. Polyurethane is obtained from the isocyanates, known worldwide for its tragic association with the Bhopal disaster. As for chlorinated rubber it derives from reacting butyl rubber with chlorine and its important to remember that chlorine is associated to the production of dioxins and furans that are extremely toxic and also biocumulative. Several scientist groups already suggest that chlorine industrial based products should be prohibited [12].

Besides recently the European Union recently approved the Regulation (EU) 305/2011 related to the Construction Products Regulation (CPR) that will replace the current Directive 89/106/CEE, already amended by Directive 1993/68/EEC, known as the Construction Products Directive (CPD). A crucial aspect of the new regulation relates to the information regarding hazardous substances [13].

Recent investigations on the geopolymer field [14] reveal a third category of mortars with high potential to enhance the durability of concrete structures.Investigations in the field of geopolymers had an exponential increase after the research results of Davidovits (1979) who developed and patented binders obtained from the alkali-activation of metakaolin, having named it after the term "geopolymer" in 1978. The technology of alkali-activation however predates this terminology by several decades [15].

For the chemical designation of the geopolymer Davidovits suggested the name "polysialates", in which Sialate is an abbreviation for aluminosilicate oxide. The sialate network is composed of tetrahedral anions $\left[\mathrm{SiO}_{4}\right]^{4-}$ and $\left[\mathrm{AlO}_{4}\right]^{5-}$ sharing the oxygen, which need positive ions such as $\left(\mathrm{Na}^{+}\right.$, $\mathrm{K}^{+}, \mathrm{Li}^{+}, \mathrm{Ca}^{++}, \mathrm{Na}^{+}, \mathrm{Ba}^{++}, \mathrm{NH}_{4}^{+}, \mathrm{H}_{3} \mathrm{O}^{+}$) to compensate the electric charge of $\mathrm{Al}^{3+}$ in tetrahedral coordination (after dehydroxilation the aluminium changes from coordination 6 (octahedral) to coordination 4 (tetrahedral). However Provis and Van Deventer [16] mentioned that the sialate nomenclature "implies certain aspects of the geopolymer gel structure which do not correspond to reality".

Provis [17] as recently presented a rigorous and useful definition of these materials: "alkaliactivated materials are produced through the reaction of an aluminosilicate-normally supplied in powder form as an industrial by-product or other inexpensive material—with an alkaline activator, 
which is usually a concentrated aqueous solution of alkali hydroxide, silicate, carbonate or sulfate". Over the last years several authors have reported research in a large number of aspects related to geopolymers.

However, very few studies have addressed the use of geopolymers for enhancement of concrete structures durability. Since geopolymer performance concerning the resistance to acid attack, is far better than that of Portland cement this means that this materials could be an alternative low toxicity, coating material.

This paper presents results of an experimental investigation on the resistance to chemical attack (with sulfuric and nitric acid) of several materials: OPC concrete, high performance concrete (HPC), epoxy resin, acrylic painting and a fly ash based geopolymeric mortar.

\section{Experimental work}

Materials, mix design, mortar and concrete mixing and concrete coating. The fly ash used in the geopolymeric mortars was supplied by Sines-EDP and according to the NP EN 450-1 it belongs to $\mathrm{B}$ class and has an $\mathrm{N}$ class fineness modulus. Geopolymeric mortars were a mixture of aggregates, fly ash, calcium hydroxide and alkaline silicate solution. The mass ratio for aggregates/fly ash and activator was $2 / 1 / 0.6$. A $10 \%$ percentage substitution of fly ash by calcium hydroxide in the mixture was also used. This is because the use of minor calcium hydroxide percentages is pivotal for the strength and durability of geopolymers [18].

The alkaline activator was prepared prior to use. An activator with sodium hydroxide and sodium silicate solution $\left(\mathrm{Na}_{2} \mathrm{O}=13.5 \%, \mathrm{SiO}_{2}=58.7 \%\right.$, and water $\left.=45.2 \%\right)$ was used with a mass ratio of 1:2.5. Previous investigations showed that this ratio lead to the highest compressive strength results in geopolymeric mortars [19].

Three different sodium hydroxide concentration (10M,14M,18M) were used. An ordinary Portland cement (CEM I 42,5 N) where used to prepare the concrete mixtures. Two concrete mixes (normal and HPC) were designed using the Faury concrete mix design method (Table 1).

Table 1 - Concrete mix proportions per cubic meter of concrete

\begin{tabular}{|c|c|c|c|c|c|}
\hline & $\begin{array}{c}\text { Cement } \\
(\mathrm{kg})\end{array}$ & $\begin{array}{c}\text { Sand } \\
(\mathrm{kg})\end{array}$ & $\begin{array}{c}\text { Coarse aggregates } \\
(\mathrm{kg})\end{array}$ & Water & W/C \\
\hline NC & 270 & 1135 & 732 & 182 & 0.65 \\
\hline BED & 442 & 876 & 782 & 205 & 0.45 \\
\hline
\end{tabular}

An expoxy resin often used as concrete coating protection against acid attack with a commercial reference Sikagard 62 PT was used for coating of the two concrete mixtures. The epoxy adhesive is a two components system (resin and hardener) with a bulk density of $1,35 \mathrm{~kg} / \mathrm{dm}^{3}$. An acrylic paint often used as concrete coating protection to prevent the access of aggressive substances with a commercial reference Sikagard - 660 ES was also used for coating of the two concrete mixtures. This material has a bulk density of $1,30 \mathrm{~kg} / \mathrm{dm}^{3}$ and is provided by the manufacturer as ready to be used.

\section{Experimental procedures}

Compressive strength. The compressive strength was performed under NP EN 206-1. Tests were performed on 100x100x100 $\mathrm{mm}^{3}$ concrete specimens. The compressive and flexural strength data of geopolimeric mortars was obtained using $160 \times 40 \times 40 \mathrm{~mm} 3$ cubic specimens according to EN 101511.

Capillary water absorption. Capillary water absorption was carried out using 40x400x80 $\mathrm{mm}^{3}$ specimens in the case of geopolymeric mortars and 100x100x100 $\mathrm{mm}^{3}$ specimens for concrete. After 28 days in a moist chamber the specimens were placed in an oven $105^{\circ} \mathrm{C}$ for $24 \mathrm{~h}$. This test his carried on according to Standard LNEC E393. 
Resistance to acid attack. The resistance to acid attack followed a variation of the ASTM C267 (Standard test methods for chemical resistance of mortars, grouts, and monolithic surfacing's and polymer concretes). Three different acids were used (sulphuric, hydrochloric and nitric). Three acid concentrations were used $(10 \%, 20 \%$ and $30 \%)$ to simulate long time exposure at lower concentrations.. The resistance to acid attack was assessed by the differences in weight of dry specimens before and after acid attack at 1, 7, 14, 28 and 56 days. The acid resistance was assessed by the differences in weight of dry specimens before and after acid attack since compressive strength of specimens immersed in acid media could not be evaluated. The fly ash based geopolymeric mortar used in the resistance to acid attack was the one associated with the highest compressive strength and low water absorption.

\section{Results and discussion}

Compressive strength. Fig. 1 shows the results of the compressive strength of the fly ash based geopolymeric mortars after 28 days curing as well as of the two concrete mixtures. The results show that the compressive strength of geopolymeric mortars is very dependent on the molarity of the sodium hydroxide. Increasing the molarity from $10 \mathrm{M}$ to $14 \mathrm{M}$ leads to a relevant compressive strength loss. However, further increase from $14 \mathrm{M}$ to $18 \mathrm{M}$ shows no noticeable effects. Previous investigations [20] have shown that although a high alkali content favours the dissolution of $\mathrm{Al}$ and $\mathrm{Si}$ species of fly ash but can also negatively affect its strength. Normal concrete (NC) has a compressive strength around 30MPa while HPC compressive strength slightly exceeds $45 \mathrm{MPa}$.

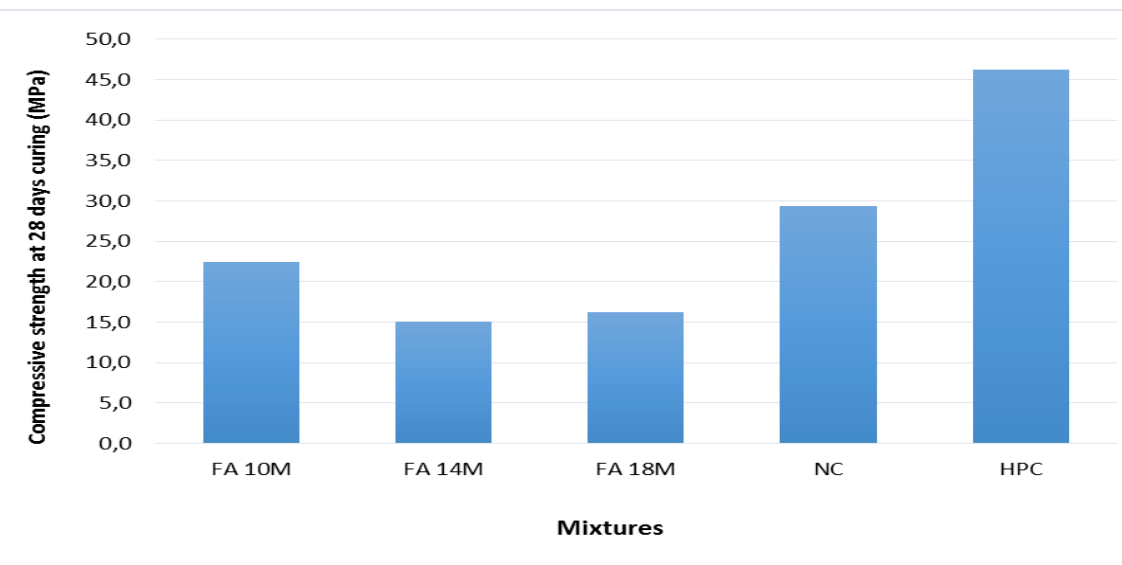

Fig. 1 - Compressive strength

Capillary water absorption. Figure 2 shows the capillary water absorption coefficients. While the fly ash geopolymeric mortars with a sodium hydroxide molarity of 14 and $18 \mathrm{M}$ show a capillary water absorption around $0.45 \mathrm{~kg} / \mathrm{m}^{2} \cdot \mathrm{h}^{0.5}$ the geopolymeric mortar with the lowest open porosity and the highest compressive strength has a $0.1 \mathrm{~kg} / \mathrm{m}^{2} \cdot \mathrm{h}^{0.5}$ capillary water absorption coefficient.The capillary water absorption of the two concrete mixes used in this investigation is very low around $0.15 \mathrm{~kg} / \mathrm{m}^{2} \cdot \mathrm{h}^{0.5}$. As a comparison a plain $\mathrm{C} 30 / 37$ strength class concrete has a capillarity coefficient of $0.251 \mathrm{~kg} / \mathrm{m}^{2} \cdot \mathrm{h}^{0.5}$ for 28 days curing [21], while a plain C20/25 strength class concrete (the most used strength class in Europe [22]) has capillarity coefficients between 0.85 and $2.6 \mathrm{~kg} / \mathrm{m}^{2} \cdot \mathrm{h}^{0.5}$ [23].

Resistance to acid attack. Fig. 3 shows the weight loss after sulphuric acid attack for the different acid concentrations. Normal concrete coated with epoxy resin shows the most stable performance for all three acid concentrations conforming previous investigations. 


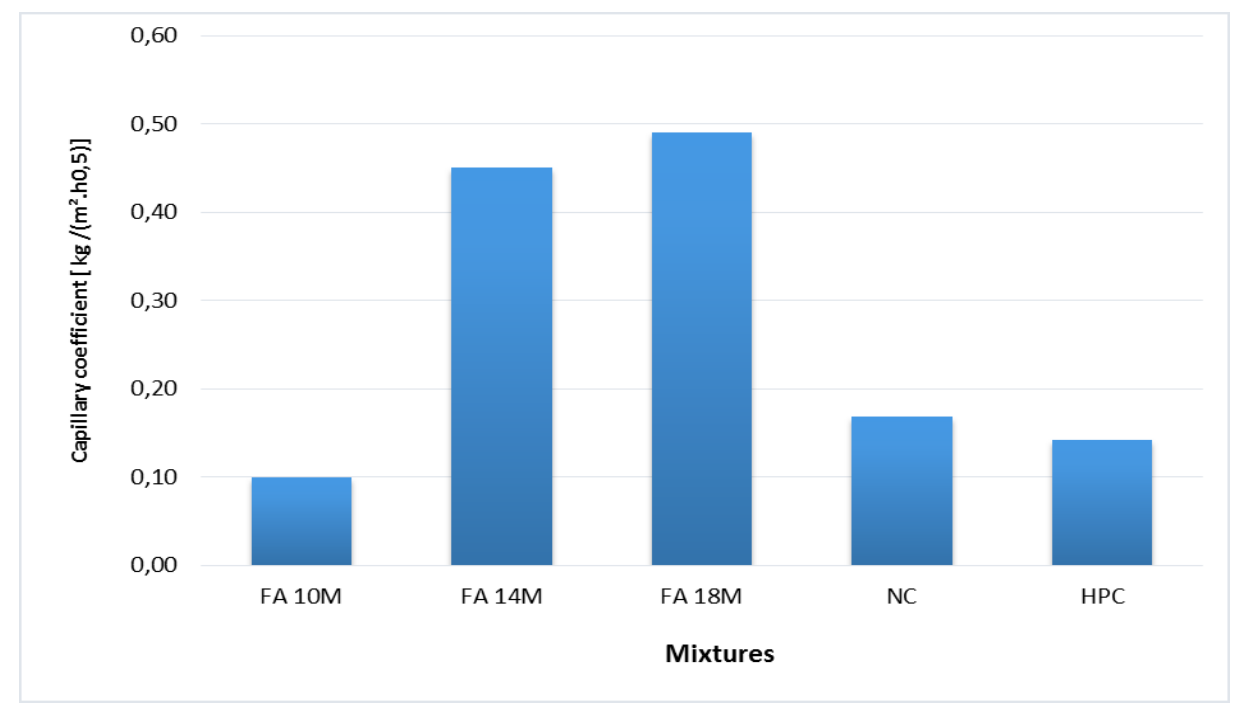

Fig. 2 - Water absorption capillary coefficients

The fly ash geopolymeric mortar shows a good performance for both 10 and 20\% sulphuric acid concentration.. Even for a 30\% sulphuric acid concentration this mortar shows a good acid resistance for immersion until 14 days. HPC specimens shows the third best performance. It shows a minor weigth loss after 56 days in a $10 \%$ sulphuric acid concentration. For a $20 \%$ sulphuric acid concentration the weight loss is clear beyond 14 days reaching a maximum of $9 \%$. When the concentration increases to $30 \%$ the weigth loss starts after 7 days inmmersion and reaches a maximum of $20 \%$ after 56 days. Specimens of normal concrete coated with acrylic paint show the same performance of uncoated concrete specimens for both 10 and $20 \%$ sulphuric acid concentration. Only for the $30 \%$ acid concentration and long-time immersion can this coat be of some use. Since NC and HPC have almost similar capillary water absorption than the differences in acid resistance lie in the leaching of calcium hydroxide $\left(\mathrm{Ca}(\mathrm{OH})_{2}\right)$ from the pore solution and decalcification of CSH that must be lower in the latter case due to a much higher Portland cement content.

Weight loss after nitric acid attack is shown in fig.4. Again normal concrete coated with epoxy resin shows the most stable performance for all three acid concentrations. Nitric acid attack at $10 \%$ concentrations is especially destructive for $\mathrm{NC}$ even after just 7 days immersion. Nitric acid reacts with calcium compounds forming calcium nitrate which has a solubility (56\%). All the other mixtures show a weight loss not exceeding $2 \%$ even after 56 immersion. The behaviour for a $20 \%$ nitric acid concentration is almost the same. The difference being that NC shows a higher weight loss. When the acid concentration is increased to $30 \% \mathrm{NC}$ does not show an increase in the weight loss. For this very high acid concentration the geopolymeric mortar shows a disappointing performance. Allahverdi and Škvára [24, 25] suggested that the electrophilic attack of nitric acid protons results in the ejection of tetrahedral aluminium from the aluminosilicate framework and in the formation of an imperfect highly siliceous framework. Other authors [26] also suggested this aluminosilicate depolymerisation.

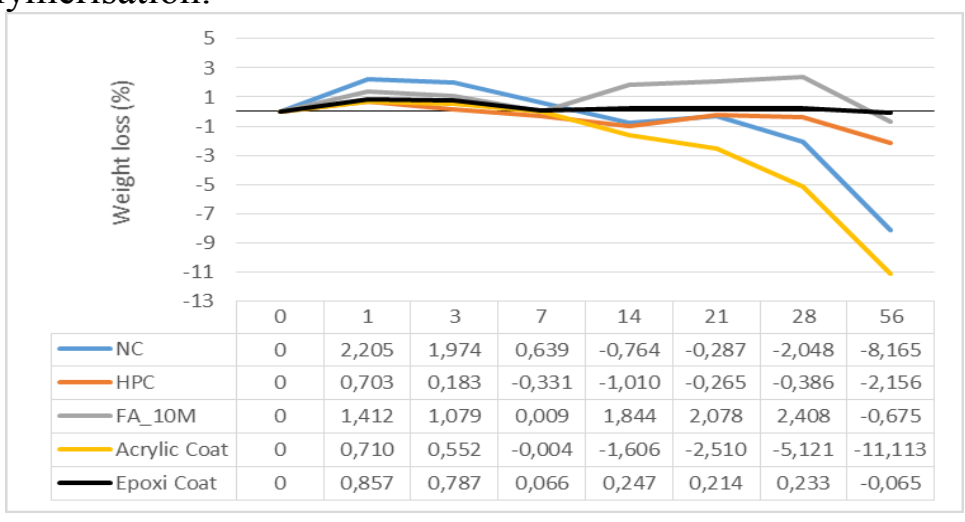


b)

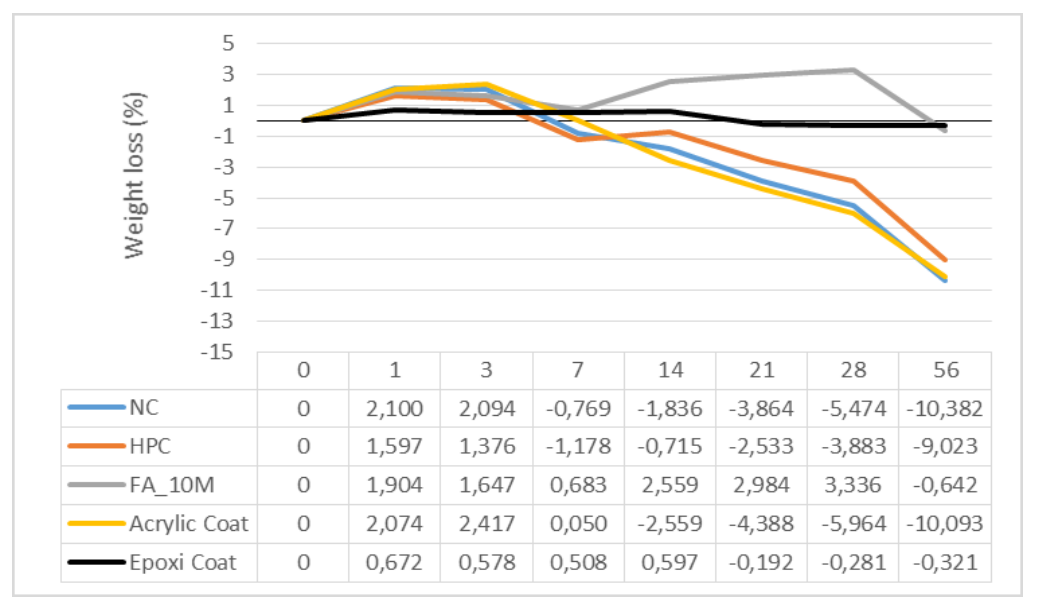

c)

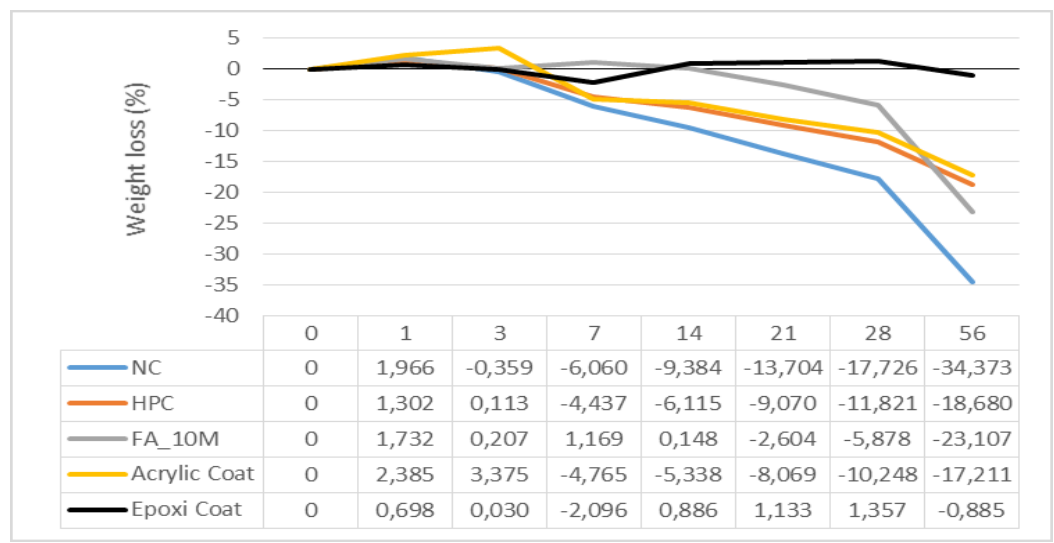

Fig. 3 - Weigth loss due to sulfuric acid attack:

a) $10 \%$ acid concentration; b) $20 \%$ acid concentration; c) $30 \%$ acid concentration

a)

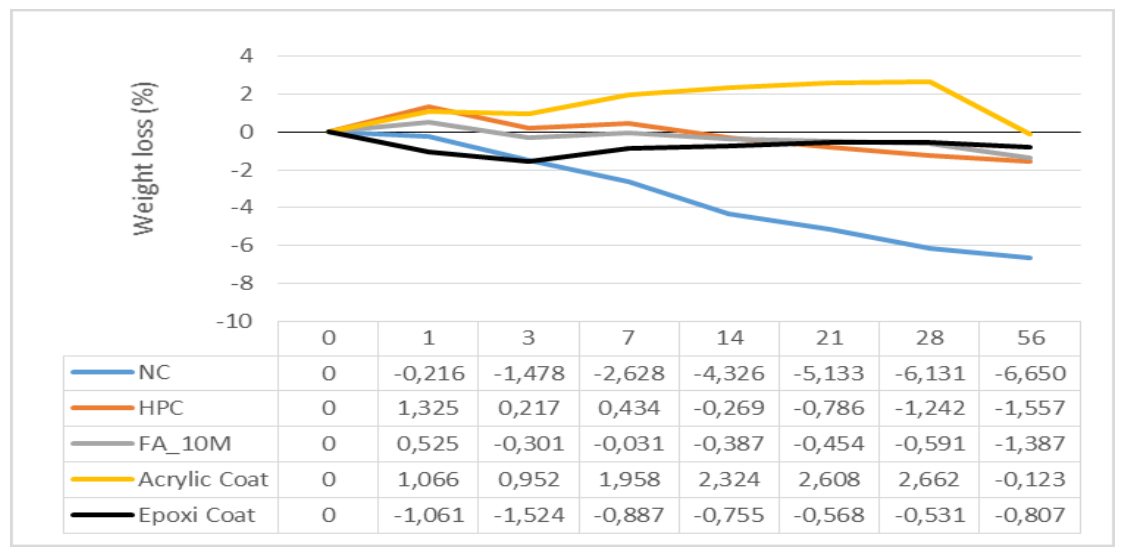

b)

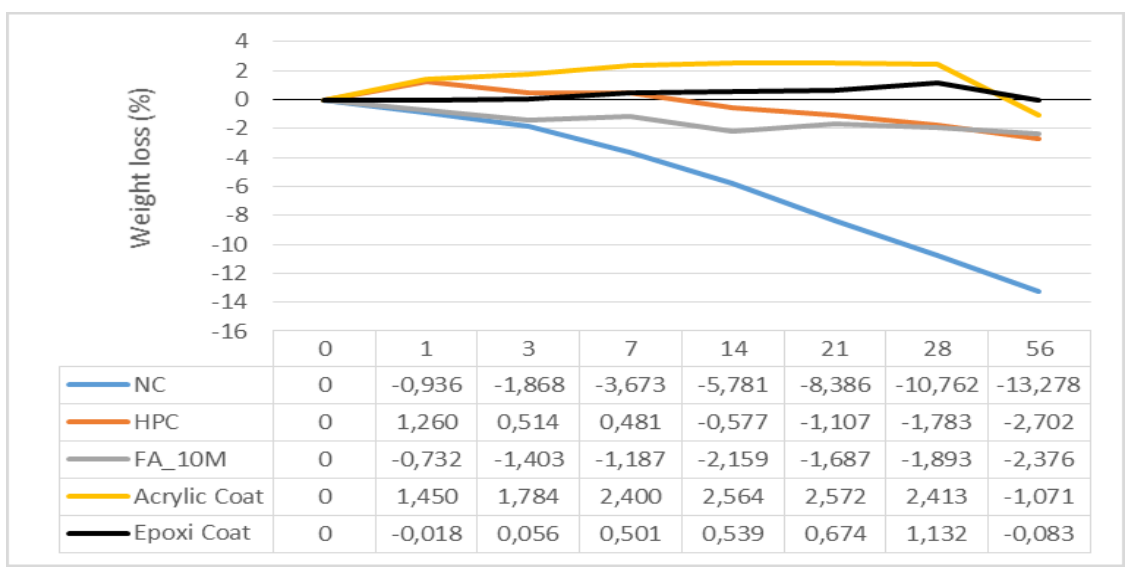


c)

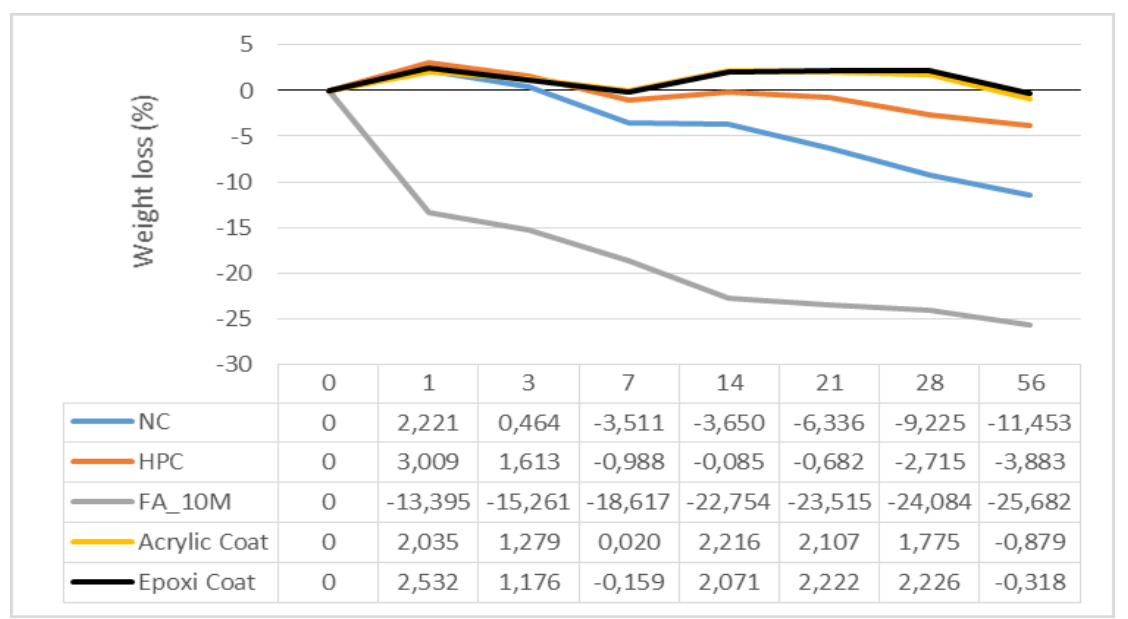

Fig. 4 - Weigth loss due to nitric acid attack:

a) $10 \%$ acid concentration; b) $20 \%$ acid concentration; c) $30 \%$ acid concentration

\section{Conclusions}

This article presents results of an experimental investigation on the resistance to chemical attack of several materials. Normal concrete coated with epoxy resin shows the most stable performance for all three acid types and acid concentrations. For a very high nitric acid concentration the geopolymeric mortar shows a disappointing performance that could be due to the ejection of tetrahedral aluminium from the aluminosilicate framework and in the formation of an imperfect highly siliceous framework.

\section{References}

[1] F. Glasser, J. Marchand, E. Samson, Durability of concrete, Degradation phenomena involving detrimental chemical reactions, Cem. Concr. Res. 38 (2008) 226-246.

[2] F. Pacheco-Torgal, J.P. Castro-Gomes, S. Jalali, Alkali - activated binders: a review Part 1 Historical background, terminology, reaction mechanisms and hydration products, Constr. Build. Mat. 22 (2008) 1305-1314.

[3] F. Pacheco-Torgal, Z. Abdollahnejad, S. Miraldo, S. Baklouti, Y. Ding, An overview on the potential of geopolymers for concrete infrastructure rehabilitation, Constr. Build. Mat. 36 (2012) 1053-1058.

[4] A. Almusallam, F. Khan, S. Dulaijan, O. Al-Amoudi Effectiveness of surface coatings in improving concrete durability, Cem. Concr. Comp. 25 (2003) 473-481.

[5] J. Aguiar, P. Moreira, P. Lukowski, L. Czarnecki, A. Camões, D. Van Gemert Ranking procedure for polymeric coatings and hydrophobic agents for concrete protection, Restoration of Buildings and Monuments 13 (2007) 251-264.

[6] J.B. Aguiar, A. Camões, P.M. Moreira, Coatings for concrete protection against aggressive environments, J. Adv. Concr. Tech. 6 (2008) 243-250.

[7] M. Berndt, Evaluation of coatings, mortars and mix design for protection of concrete against sulphur oxidising bacteria, Constr. Build. Mat. 25 (2011) 3893-3902.

[8] M. Medeiros, P. Helene, Efficacy of surface hydrophobic agents in reducing water and chloride ion penetration in concrete, Mater. Struct. 41 (2008) 59-71.

[9] F. Pacheco-Torgal, S. Jalali, Sulphuric acid resistance of plain, polymer modified, and fly ash cement concretes. Constr. Build. Mater. 23 (2009) 3485-3491. 
[10] A. Brenna, F. Bolzoni, S. Beretta, M. Ormellese, Long-term chloride-induced corrosion monitoring of reinforced concrete coated with commercial polymer-modified mortar and polymeric coatings, Constr. Build. Mat. 48 (2013) 734-744.

[11] J. Bijen, Durability of engineering structures, Design, repair and maintenance, Woodhead Publishing Limited, Abington Hall, Cambridge (2000).

[12] F. Pacheco-Torgal, S. Jalali, Toxicity of building materials, A key issue in sustainable construction. International Journal of Sustainable Engineering, Taylor \& Francis 4, (2011) 281-287.

[13] F. Pacheco-Torgal, S. Jalali, A. Fucic, Toxicity of Building Materials, Woodhead Publishing Limited, Cambridge (2012).

[14] F. Pacheco-Torgal, J.P. Castro-Gomes, S. Jalali, Adhesion characterization of tungsten mine waste geopolymeric binder. Influence of OPC concrete substrate surface treatment, Constr. Build. Mater. 22 (2008) 154-161.

[15] F. Pacheco-Torgal, J.A.Labrincha, C. Leonelli, A. Palomo, P. Chindaprasirt, Handbook of Alkali-Activated Cements, Mortars and Concretes ed., 1. Abington Hall, Cambridge, UK: WoodHead Publishing Limited- Elsevier Science and Technology (2014)

[16] J. Provis, J.S.J. Van Deventer, Geopolymers: Structure, Processing, Properties and Industrial Applications, Woodhead Publishing, Cambridge, UK (2009)

[17] J. Provis, Geopolymers and other alkali activated materials: why, how, and what ? J. Mat. Struct. 47 (2014) 11-25.

[18] J.S.J.Van Deventer, J. Provis, P. Duxson, Technical and commercial progress in the adoption of geopolymer cement", Min. Eng. 29, (2012) 89-104.

[19] F.Pacheco-Torgal, J.P. Castro-Gomes, S. Jalali, Investigations on mix design of tungsten mine waste geopolymeric binders, Constr. Build. Mat. 22 (2008) 1939-1949.

[20] W.K.Lee, J.S.J.Van Deventer, The effect of ionic contaminants on the early-age properties of alcali-activated fly ash-based cements, Cem. Concr. Res. 32 (2002) 577-584.

[21] R. Ferreira, Evaluation of durability test, Master Thesis, University of Minho, Guimaraes, Portugal (2000).

[22] ERMCO - European ready-mixed concrete industry statistics - 2013 (2014).

[23] F. Pacheco-Torgal, J.P. Castro-Gomes, Influence of physical and geometrical properties of granite and limestone aggregates on the durability of a C20/25 strength class concrete, Const. Build. Mat. 20 (2006) 1079-1088.

[24] A. Allahverdi, F. Škvára, Nitric acid attack on hardened paste of geopolymeric cements, Part 1, Ceram -Silik, 45 (2001) 81-88.

[25] A. Allahverdi, F. Škvára, Nitric acid attack on hardened paste of geopolymeric cements, Part 2, Ceram -Silik, 45 (2001) 143-149.

[26] A. Fernandez-Jimenez, I. Garcıa-Lodeiro, A. Palomo, Durability of alkali-activated fly ash cementitious materials, J. Mater. Sci. 42 (2007) 3055-3065. 